\title{
CONSTRUÇÃO DO CALENDÁRIO AGRÍCOLA PARA O MUNICÍPIO DE ITABERABA, BASEADO NA SÉRIE HISTÓRICA DE 1993 A 2013
}

\author{
$\underline{\text { Iverson Lima da Mota }}{ }^{1}$; Manuel Cabalar Fuentes ${ }^{2}$; Deorgia Tayane Mendes de \\ Souza $^{3}$ \\ 1. Bolsista PIBIC/FAPESB, Graduando em Geografia, Universidade Estadual de Feira de Santana, e-mail: \\ Iverson_mota09@hotmail.com \\ 2. Orientador, Departamento de Ciências Humanas e Filosofia, Universidade Estadual de Feira de Santana, e-mail: \\ manuel.cabalar@gmail.com \\ 3. Co-orientadora, Departamento de Ciências Humanas e Filosofia, Universidade Estadual de Feira de Santana, e- \\ mail: Deorgiasouza@yahoo.com.br
}

PALAVRAS-CHAVE: calendário agrícola; agricultura de sequeiro; precipitação pluviométrica.

\section{INTRODUÇÃO}

O Estado da Bahia apresenta cerca de $70 \%$ de sua área sob o domínio semiárido (Projeto Áridas/CARAOUAD, 1995). A irregularidade pluviométrica é um traço marcante no estado o que, sem um monitoramento das quantidades e períodos de chuva, torna $\mathrm{o}$ ato de produzir no Sertão uma tarefa desafiadora. O município de Itaberaba é um retrato deste território, onde está presente as atividades de agricultura de sequeiro e criação de animais, portanto estas intempéries afetam diretamente a vida destes produtores rurais, que carecem de informações meteorológicas adequadas para preparar o solo, semear, plantar e colher no momento mais oportuno.

Com base na análise da rede meteorológica do estado da Bahia, voltando-se os estudos para a construção do Calendário Agrícola do município de Itaberaba, foi possível caracterizar os níveis de pluviosidade atrelados aos números das produções das culturas do abacaxi, da mandioca e do feijão, interpretando e indicando os meses mais adequados para cada etapa da produção. O calendário agrícola para estas culturas, além de ser um meio para se planejar com mais eficiência a produção agrícola do município, é um instrumento de comunicação e divulgação sobre a variabilidade meteorológica do município estará acessível ao pequeno proprietário rural. Saber o reparto sazonal dos volumes de chuvas e como elas irão repercutir no plantio dos produtos, com uma linguagem de fácil compreensão e um meio facilitado de acesso, vai promover um melhor planejamento de sua atividade agrícola e fazê-lo tomar medidas preventivas quanto aos problemas climáticos.

\section{MATERIAL E MÉTODOS OU METODOLOGIA}

A primeira etapa do trabalho consistiu na realização da revisão bibliográfica para que se pudesse dar embasamento teórico a pesquisa, bem como, para melhor compreender de que forma ocorre a produção agrícola no município de Itaberaba.

A etapa seguinte consistiu na aquisição de dados meteorológicos do município de Itaberaba-BA da série histórica de 1993 a 2013 disponibilizados pelo Instituto Nacional de Meteorologia (INMET), a partir dos dados de precipitação pluviométrica foi possível compreender a variabilidade meteorológica da área de estudo ao longo dos anos analisados. Posteriormente foi realizado a aquisição dos dados que dizem respeito à produção agrícola no município para os anos analisados, dados estes disponibilizados pelo Instituto Brasileiro de Geografia e Estatística (IBGE), a partir da aquisição destes 
dados foram escolhidas três culturas para serem trabalhadas, sendo estas as culturas do abacaxi, da mandioca e do feijão, são estas duas últimas culturas eminentemente de sequeiro, ou seja que não utilizam técnicas agrícolas de irrigação, tornando-se assim culturas bastantes susceptíveis às variações meteorológicas. A produção do abacaxi apesar de não ser qualificada como agricultura de sequeiro, pois é uma cultura que faz uso das técnicas de irrigação, foi também trabalhada no presente estudo por corresponder a principal produção agrícola no município, cultura esta que se desenvolveu bastante ao longo dos anos no município de Itaberaba, dando destaque ao referido município no estado da Bahia.

Após ter realizado a aquisição de todos os dados (meteorológicos e de agricultura) foi feito a integração dos dados utilizando as médias anuais de chuvas do período obtidas, com os dados da relação de área plantada e área colhida das três culturas escolhidas para serem trabalhadas, construindo-se assim gráficos de produção no município para embasar a construção do Calendário Agrícola de Itaberaba. Por meio destes primeiros gráficos, foi possível identificar os anos que apresentaram as maiores e as menores produções agrícolas associados com a variabilidade meteorológica do município, assim foram escolhidos dois anos de produção positiva e dois anos de produção negativa, dentre as culturas selecionadas, para que se pudesse analisar a distribuição temporal das precipitações pluviométricas nos meses destes anos, possibilitando assim a realização do Calendário Agrícola fazendo uso da análise dos resultados obtidos de acordo com os meses mais chuvosos o preparo do solo, plantio e tempo de crescimento; e os meses menos chuvosos a colheita e o descanso do solo.

\section{RESULTADOS E/OU DISCUSSÃO (ou Análise e discussão dos resultados)}

Apesar do curto período em que o presente estudo foi desenvolvido (7 meses), foi realizada uma breve análise das condições meteorológicas que o município de Itaberaba-BA apresentou na escala temporal estudada que corresponde aos anos de 1993 a 2013, compreendendo também a influência que a meteorologia exerce sobre as culturas analisadas no município.

Foi realizado uma análise preliminar das condições físico-ambientais do município por meio de mapas para que pudesse compreender como alguns elementos se espacializam e acabam favorecendo a agricultura, assim foram gerados e analisados ao longo da pesquisa mapas de geologia, geomorfologia, altimetria e solos.

Posteriormente deu-se seguimento os gráficos que foram gerados possibilitando a análise dos dados meteorológicos, para tanto, foram levados em considerações as culturas de maior expressão no município, sendo que estas foram cultivadas em praticamente todos os anos (1993 - 2013) do presente estudo. Assim, entre as lavouras temporárias que foram cultivadas no município, optou-se pela análise dos cultivos do abacaxi, da mandioca e feijão, sendo estas, lavouras que compõem a chamada agricultura de sequeiro, pois não se utilizam de técnicas agronômicas de irrigação, exceção somente as culturas do abacaxi que fazem usos destas técnicas, sendo este produto escolhido para análise no presente estudo por se tratar do principal produto agrícola do município de Itaberaba-BA.

Por meio dos gráficos ficou perceptível que o abacaxi teve uma rápida valorização, pois as condições ambientais que o município apresenta juntamente com técnicas agrícolas 
de irrigação, manejo e controle de pragas, favoreceram o desenvolvimento do produto no município, o abacaxi passou a ser assim, a principal cultura produzida no município de Itaberaba. Porém, esta súbita valorização do abacaxi teve um impacto negativo sobre as demais culturas que antes eram produzidas no município, pois diversos agricultores optaram pelo plantio do abacaxi por ser mais rentável e não depender tanto das precipitações pluviométricas por utilizar técnicas de irrigação agrícola, uma das culturas que sofreu bastante o impacto da supervalorização do abacaxi no município de Itaberaba foi a da mandioca, sendo que este produto já vinha sendo desvalorizado, acentuando ainda mais essa desvalorização devido ao fato de que as culturas da mandioca serem de sequeiro atrelado ao desenvolvimento do abacaxi, onde produtores rurais que antes produziam mandioca e outras culturas passaram a desenvolver exclusivamente o cultivo do abacaxi. O cultivo do feijão é o que mais está associado as variabilidades meteorológicas, pois em anos que a precipitação pluviométrica foi bastante reduzida os cultivos do feijão também foram bastantes inferiores, quando não acarretaram em perdas na produção.

A confecção do calendário agrícola das culturas estudadas no município de ItaberabaBA foi obtida analisando todos os gráficos utilizados no estudo, uma vez que, os primeiros gráficos de cada cultura demonstraram um panorama geral da produção de cada cultura atrelado as variabilidades meteorológicas, por meio destes gráficos analisou-se os anos de produção positiva, em que não foram registradas perdas na produção e os anos de produção negativa em que houveram perdas na produção.

Tabela 1 - Calendário Agrícola do município de Itaberaba-BA

\section{CULTURA INÍCIO DO PLANTIO INÍCIO DA COLHEITA}

\begin{tabular}{ccc}
\hline ABACAXI & Janeiro/dezembro & Janeiro/dezembro \\
FEIJÃO 1 & & Março/abril \\
FEIJÃO 3 & Novembro/dezembro & Agosto/setembro \\
MANDIOCA & Maio & Janeiro/dezembro \\
\hline
\end{tabular}

A partir da confecção do Calendário Agrícola o produtor rural poderá ter ao seu alcance uma ferramenta de fácil compreensão que se objetiva em auxiliar no planejamento quanto aos períodos de plantio e colheita das culturas estudas, minimizando assim, eventuais perdas na produção ocasionadas pela variabilidade meteorológica no município. A cultura do abacaxi como já ressaltado durante o trabalho, não é uma lavoura de sequeiro estando apta ao cultivo ao longo do ano, pois utiliza-se de técnicas de irrigação, porém é necessário salientar que é imprescindível que produtor do abacaxi reduza as irrigações em períodos chuvosos, pois a elevada umidade por longo período de tempo pode favorecer a proliferação de pragas que atentem contra as lavouras, como ocorreu nos anos de 2006 e 2008 momentos em que foram registrados perdas por conta da propagação de pragas do abacaxi. O feijão pode ser em cultivado no município 
principalmente em duas safras distintas, sendo que a primeira o início do plantio ocorre entre os meses de novembro a dezembro vindo a ser colhida a safra entre os meses de março e abril, esta safra é marcada pela elevação das precipitações pluviométricas. A chamada terceira safra do feijão tem início no mês de maio sendo a safra colhida entre os meses de agosto a setembro, neste período as precipitações pluviométricas são mais reduzidas, caracterizando assim um período mais seco no município. A mandioca apesar da desvalorização que teve ao longo dos anos e apresentando pequenas lavouras ainda se constitui num importante produto, esta deve ser plantada entre junho e dezembro, que são meses que em que a precipitação pluviométrica tende a aumentar, ocorrendo boa distribuição de chuvas poderá a mandioca ser colhida ao longo de todo o ano.

\section{CONSIDERAÇÕES FINAIS}

Os objetivos traçados para este estudo foram alcançados, uma vez que foi possível desenvolver uma análise das condições atmosféricas encontradas no município de Itaberaba-BA numa série histórica de 1993 a 2013 associada a produção das culturas do abacaxi, da mandioca e do feijão, sendo estas duas últimas lavouras de sequeiro que não utilizam técnicas de irrigação agrícolas o que as tonam mais susceptíveis as oscilações meteorológicas, o abacaxi por sua vez faz uso de técnicas de irrigação.

Por meio deste estudo observa-se que as produções agrícolas no município de Itaberaba não estão recebendo a mesma valoração que a produção do abacaxi, na série histórica dos cultivos analisados ficou perceptível a supervalorização e este cultivo vem tendo, isto demonstra um impacto negativo para as demais culturas. As grandes oscilações meteorológicas que na maior parte das vezes afetam os cultivos de forma negativa estão associadas ao fenômeno El Niño que exerce influência sobre a meteorologia em escala mundial.

Após serem gerados os gráficos de precipitação pluviométricas dos anos que apresentaram produção das três culturas (abacaxi, feijão e mandioca) foi possível compreender como as chuvas se distribuem ao longo dos anos e de que forma exerce influência negativa e positiva sobre as plantações no município de Itaberaba-BA, possibilitando assim realizar um calendário agrícola que indique os melhores períodos para a realização do plantio e da colheita para cada uma das três culturas estudadas.

\section{REFERÊNCIAS}

DINIZ, Aline Franco. Estudo da Variabilidade da Pluviosidade (1994-2010) no Município de Feira de Santana (Bahia) e seus Reflexos na Agricultura de Sequeiros: o caso do milho. 2012, 114 p. Dissertação (Mestrado) - Programa de Pós-Graduação do Departamento de Geografia do Instituto de Geociências, Universidade Federal da Bahia, Salvador, 2012.

MENDONÇA, Francisco; DANNI - OLIVEIRA, Inês Moresco. Climatologia - noções básicas e clima do Brasil. São Paulo: Oficina de Texto, 2007.

SILVA, Osmira Fátima da; WANDER, Alcido Elenor. O feijão-comum no Brasil : passado, presente e futuro. - Santo Antônio de Goiás : Embrapa Arroz e Feijão, 2013.

Disponível em: http://www.itaberabanoticias.com.br/sobre-itaberaba/cultura-do-abacaxi acesso em : 13/05/16

Disponível em: http://www.agencia.cnptia.embrapa.br/gestor/feijaocaupi/arvore/CONTAG01_17_510200683536.html acesso em: 15/05/16 